\title{
Plans and Strategies for UBcN Networks and Services
}

\author{
Eunyoung Lee*
}

\begin{abstract}
The broadcasting \& telecommunication services in the future will be converged and be serviced on mobile devices. However, the current ICT infrastructure does not fully meet the future demand for those converged, realistic, intelligent, and personalized services. The Korean government is going to establish a high speed next generation network called UBcN (Ultra-Broadband Convergence Network) by 2013. The Korean government has announced a multi-year plan to establish an UBCN network and to discover and stimulate new converged services for an UBcN in January, 2009. The author of this paper has taken part in formulating development plans since the early stages of planning. In this paper, Korea's development plans for the next generation network and their development strategies are analyzed and discussed based on the author's experience. The paper also discusses the expected impacts of the plan for the future ICT industry, and the implications of government-driven development plans.
\end{abstract}

Keywords-UBcN, Broadband, NGN, Converged Services, Policies

\section{INTRODUCTION}

Convergence of integrated terminals and services is expanding, through which all types of information such as voice, data, images and multi-media are converged. Convergence between industries and services is further accelerated due to information technology developments such as telematics, u-Health, u-Learning, u-City, and so on. The world is moving towards an integrated digital economic system in which distinctions between economic activities disappear. The broadcasting \& telecommunication services in the future will be converged and be serviced on mobile devices. MPS (Multiple Play Service) beyond TPS (Triple Play Service) or QPS (Quadruple Play Service) will be provided to combine voice calls and Internet and broadcasting in various environments including the mobile environment. Also, SoTV (Service over TV) seems likely to emerge, which combines various application services such as education, healthcare, and civil services through interactive digital TV. It is also expected that the services in the future will be more intelligent, more personalized and more realistic.

Although there has been continuous improvement, the current ICT infrastructure does not fully meet the future demand for the new converged, realistic, intelligent, and personalized services. Regarding aspects such as speed, coverage, interoperability, quality and security, the current ICT infrastructure leaves much to be desired. For example, one household will consume $125 \sim 285 \mathrm{Mbps}$ bandwidth on average on a fixed-line network and one user will consume about

\footnotetext{
Manuscript received February 18, 2010; accepted August 7, 2010.

Corresponding Author: Eunyoung Lee

* Dept. of Computer Science, Dongduk Women’s University, Seoul, Korea (elee@dongduk.ac.kr)
} 
$10 \mathrm{Mbps}$ on average on a wireless network for MPS which is likely to comprise the major portion of broadcasting and telecommunication services in the near future. A rich, high-density and realistic media service will also be available soon, which provides images $4 \sim 16$ times clearer than those of full HDTV. In this case, one household will consume an additional $100 \mathrm{Mbps}$ of bandwidth (based on a fixed line).

The problem is that the required bandwidth is not quite satisfied by the current ICT infrastructure. In fact, Korea possesses the world's top class information infrastructure through continuous projects since 1995. As the result of previous projects, the high-speed information and communications networks of Korea function as fast as $1.5 \sim 2 \mathrm{Mbps}$, and the Broadband convergence Network $(\mathrm{BcN})$ of Korea perform as fast as or faster than $50 \mathrm{Mbps}$. Although Korea is ranked first in the world in the digital opportunity index (DOI) and third in the national computerization index as of 2007, the need for high-speed networks has been accelerated by digital convergence, that is, the convergence of broadcasting, communications and the Internet.

To satisfy the future demand for converged, realistic, intelligent and personalized services, it seems inevitable to develop a faster and more robust network infrastructure with effective strategies. In January 2009, the Korean government announced a plan to establish a next generation network which provides higher speeds for the new converged services. The new network infrastructure is called UBcN (Ultra-Broadband Convergence Network). The main goal of the $\mathrm{UBcN}$ development is to establish an information and communications environment in which anybody can use converged network services anytime and anywhere with convenience. In order to achieve this goal, the $\mathrm{UBcN}$ will be upgraded to a 46 million-subscriber network with speeds of 1Gbps by 2013. It is expected that the improved speed of fixed-line subscribers will go up to $1 \mathrm{Gbps}$ and that the speeds for wireless subscribers will go up to $10 \mathrm{Mbps}$ on average by 2013 when the deployment of the $\mathrm{UBcN}$ plan is over. $\mathrm{UBcN}$ development strategies are needed to cope with the trends of broadcasting and telecommunication networks after $\mathrm{BcN}$, future service requirements and intensive global competition.

In Section 2, the outcome of Korea's previous $\mathrm{BcN}$ projects is discussed and the current status of ICT infrastructure is explained. The major goals and strategies of the UBCN development plan will be given in Section 3. The expected effects and the plan's implications will be analyzed and discussed in Section 4. Finally conclusions will be drawn in Section 5.

\section{Current Status Analysis}

In the very near future, broadcasting and telecommunication services will be combined in the form of a converged service with voice, data, wired, wireless, and communications, broadcasting which are usable anytime, anywhere (ubiquitous), seamlessly, and safely [1,2].

The market of Information and Communications Services is expected to achieve 62.4 trillion won by 2010; up from the 46 trillion won of 2004 with an annual average growth rate of $5.2 \%$. The 2010 prospect of the second-phase plan for establishing $\mathrm{BcN}$ was raised by $8.5 \%$ compared with the previous prospect of 57.5 trillion won. The annual growth rate from 2004 to 2007 was $5.5 \%$ on average, but for the period from 2008 to 2010 about a 5.2\% annual average is expected of the matured market of information and communications services. The market of $\mathrm{BcN}$ Communications and Broadcasting Devices is expected to grow up to 9.7 trillion won by 2010 at an annual growth rate of $7.5 \%$ on average from 6.3 trillion won in 2004 . The 2010 prospect of 
the second phase plan for establishing $\mathrm{BcN}$ was raised by $2.1 \%$ compared to the previous prospect of 9.5 trillion won.

Demand for next generation network devices is expected to increase as the communicationsbroadcasting convergence environment changes and the optical subscriber network expands. At the same time, replacement demand for digital devices and broadcasting equipment is expected to steadily grow as the world-wide digital television transition nears completion. However, the broadcasting equipment market is expected to record negative growth in 2009 due to the slowed market of world digital media equipment and the relocation of foreign operations.

Significant investments towards the establishment of BcNs have been made over the last 5 years. Private sector investments of around 25.2 trillion won were generated for $\mathrm{BcN}$ transport networks, subscriber networks, and control networks through the leading investment of 618.4 billion won from 2004 to 2007. Additional network investments of 18.2 trillion won from the private sector are expected over the next three years [3].

Establishment of BcN transport networks (premium networks) by major wired operators has begun in earnest. KT established a nation-wide transport network by the end of 2007 and Hanaro Telecom and LG Dacom respectively established premium nodes throughout the major metropolitan cities. Upgrading of the wired/wireless $\mathrm{BcN}$ subscriber networks was achieved earlier through the promoted investment by the $\mathrm{BcN}$ base and conditions were established. The subscriber network of the wired service of 7.01 million and the wireless service of 5.63 million as of the end of December, 2007 have upgraded to $\mathrm{BcN}$, and public communications benefit has increased by the provision of broadband multi-media service to a total 12.64 million households and subscribers.

During the previous phases, new BcN-based service models and supporting commercialization have been created and verified. A network test-bed was established and trial services were developed and provided to nation-wide households of about 2,700 through the four grand consortiums for BcN pilot businesses. Twenty five new services including IPTV, VoIP/Video phone and u-Work were created and verified [4, 5]. Also, the commercialization of 14 services such as TV portals, interactive digital CATV (SD), WPABX (IP-based Wireless Private Automatic Branch Exchange) was supported.

BcN pilot business consortiums generated investments amounting to 145.9 billion won from 2004 to 2007 (government - 23.4 billion won). BcN core technologies and commercial network applications have been developed. Core technologies such as QoS provision, Network Control Platforms (NCP) and the optical subscriber network sectors were timely developed and commercial networks began to support $\mathrm{BcN}$ key functions such as service guarantees, broadband, IPv6 and seamless service. The following are achievements as of 2006, 49 cases of key technology development, 80 cases of technology transfer, and 3.64 billion won in technology fees. Establishing networks in which the end-to-end quality of $\mathrm{BcN}$ service is guaranteed is made possible by preparing BcN service quality standards and establishing a measurement and evaluation system. Quality standards for the BcN VoIP/Video phone (wired) service were established $[5,6]$.

A suite of software for quality measurement was developed and the technology was transferred to a total of 12 businesses including communications operators, equipment manufacturers, and terminal manufacturers (February, 2007) [7]. Information Security Guidelines and VoIP Service Information Security Guidelines in BcN transport networks and linkage areas were developed and distributed (2006). Conditions for open service (Open-API) 
activation were prepared, through which services can be developed and offered regardless of types of communications networks and operators in order to promote the development and use of the BcN-based various application services.

As a result of these $\mathrm{BcN}$ foundational accomplishments, production of the $\mathrm{BcN}$ communications and broadcasting equipment amounts to 32.9 trillion won, and accumulated exportation reached to about 10.2 billion dollars by 2007. As of 2007, the $\mathrm{BcN}$ related industry held $12.9 \%$ of production and $6.7 \%$ of exportation in the overall communications and broadcasting equipment industry and contributed to economic development [8, 9].

\section{Major Plans of UBcN DeVelopment}

\subsection{UBcN development plans}

Table 1 shows the leading trends in the network policies of advanced countries including Japan, the U.S. and the European Union. They all try to secure technological competitiveness and to preempt the market in future network areas. The goals of Korea's UBcN plan are to build a good infrastructure, and to provide world-class converged broadcasting and telecommunication services [10]. Figure 1 shows that the history of development of networks since establishing ADSL started in 1998. It also shows Korea' s plan to construct a 2-way information ultrahighway by 2012, which will be the first in the world. Achieving these goals requires developing core technologies and it is a necessary condition to enter into overseas markets. The goals can be categorized into 6 areas: backbone networks, fixed-line subscriber networks, wireless subscriber networks, broadcasting networks, sensor networks and services. In the remaining section, each area mentioned among the goals will be explained in detail.

To strengthen the backbone networks, the phone networks and mobile communication networks will be integrated with the backbone network with supporting IP protocol. The fixedline phone network (PSTN) will be switched into the IP by 2010, and the local call sector will be integrated completely with the all-IP network by 2015. IP switchover of the mobile phone network will be enhanced in line with WiBro, and will be established in 3.9G/4G eventually, which is equipped by IP.

A service control platform of the wired/wireless network based on the IMS (IP Multimedia Subsystem) will be developed. The platform will be used for providing converged, intelligent, personalized and customized services. The platform will be designed to provide uninterrupted

Table 1. Status of Future Network Implementation of Major Countries

\begin{tabular}{c|l|l|l}
\hline Item & \multicolumn{1}{|c|}{ GENI (U.S.) } & \multicolumn{1}{c}{ FIRE (Europe) } & \multicolumn{1}{c}{ NGN (Japan) } \\
\hline Objective & $\begin{array}{l}\text { Global Environment for } \\
\text { Network Innovation }\end{array}$ & $\begin{array}{l}\text { Future Internet Research } \\
\text { and Experimentation }\end{array}$ & $\begin{array}{l}\text { New Network for New } \\
\text { Generation }\end{array}$ \\
\hline Features & $\begin{array}{l}\text { Concentrated study on } \\
\text { alternative IP technology } \\
\text { and combined technology } \\
\text { like security and sensors }\end{array}$ & $\begin{array}{l}\text { Concentrated study on } \\
\text { wireless communication } \\
\text { and context-recognition } \\
\text { technology }\end{array}$ & $\begin{array}{l}\text { Concentrated study on } \\
\text { alternative IP technology, and } \\
\text { wireless and optical } \\
\text { communication technology }\end{array}$ \\
\hline $\begin{array}{c}\text { Budget/ } \\
\text { Period }\end{array}$ & $\begin{array}{l}400 \text { million US dollars } \\
(2004-2013)\end{array}$ & $\begin{array}{l}40 \text { million Euros } \\
(2007-2013)\end{array}$ & $\begin{array}{l}30 \text { billion yen } \\
(2008-2015)\end{array}$ \\
\hline
\end{tabular}




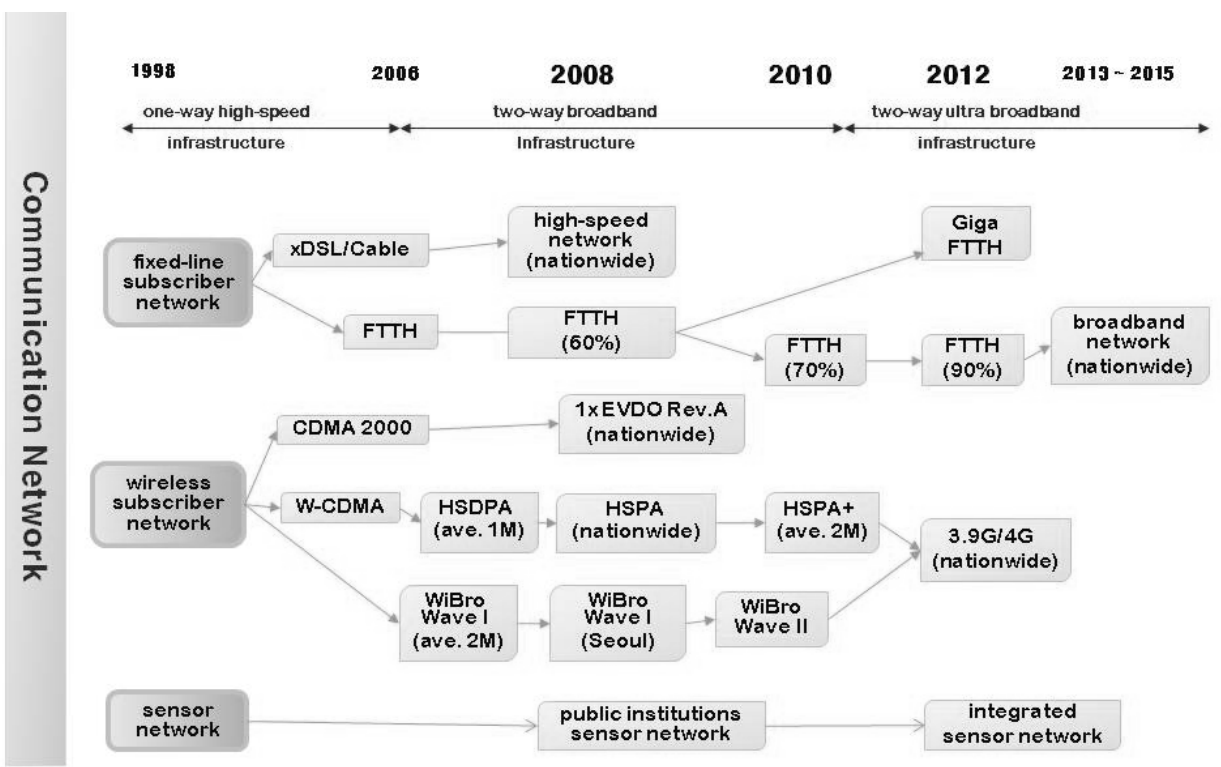

Fig. 1. Plans of Korea for Advancing Networks

portability among heterogeneous networks such as Wi-Fi, HSDPA and WiBro.

To enhance the fixed-line subscriber network, the BcN subscription target area will be extended continuously. BcN coverage will be expanded to rural areas and the existing xDSL methods will be switched to FTTH for single-family houses and LAN for apartments. Commercial Giga-Internet service will be provided from 2012 mainly within the metropolitan area after establishing the ultra-broadband subscriber network.

For enhancing the wireless subscriber network, the WiBro network will be expanded to cover up to 84 cities in 2009, and the average speed of mobile communication networks such as HSPA will be increased from $1 \mathrm{Mbps}$ to $2 \mathrm{Mbps}$ by introducing HSPA+ technology. In 2013, a total of 300,000 subscribers will be accommodated by establishing a nationwide network to provide 3.9G/4G commercial services with 10Mpbs-level on average. Femtocell technology will be applied to expand the WiBro coverage and to provide HSDPA broadband service. Table 2 shows the goals of improving subscriber networks by phase.

Broadcasting networks will be improved as follows: first of all, terrestrial broadcasting will introduce interactive service by 2010, and digital broadcasting coverage will be expanded by 96\% by 2013.The interactive service for terrestrial DMB will be introduced by 2010 and ATDMB (Advanced T-DMB) will be commercially serviced by 2012. At the same time, the coverage of digital cable TV will be expanded by $96 \%$ by 2013. Experiments in Digital radio broadcasting services will be conducted comparing various methods of digital radio broadcasting until a standard digital radio method is determined by 2010. The test broadcasting will begin by 2012 .

UBcN also includes sensor networks. The sensor networks, which have been operated independently by public agencies or other entities so far, will be linked and integrated into the all-IP broadcasting and telecommunication network. The combined network will be used as a 
Table 2. The goal of advancing network subscribers by phase

\begin{tabular}{|c|c|c|c|c|c|c|}
\hline \multirow{2}{*}{\multicolumn{2}{|c|}{ Network Type }} & \multicolumn{2}{|c|}{ Phase 1 (2009-2010) } & \multicolumn{3}{|c|}{ Phase 2 (2011 - 2013) } \\
\hline & & 2009 & 2010 & 2011 & 2012 & 2013 \\
\hline $\begin{array}{c}\text { Wired } \\
\text { Broadband } \\
(50 \sim 100 \mathrm{M})\end{array}$ & $\begin{array}{l}\text { Deployment } \\
\text { ratio }\end{array}$ & Over 65\% & Over $70 \%$ & Over $80 \%$ & Over $90 \%$ & Over 95\% \\
\hline $\begin{array}{c}\text { Wired } \\
\text { Broadband } \\
(50 \sim 100 \mathrm{M})\end{array}$ & $\begin{array}{l}\text { Subscriber } \\
\text { (million) }\end{array}$ & 11 & 12 & 13 & 14 & 14.5 \\
\hline $\begin{array}{l}\text { Wired } \\
\text { Ultra- broadband } \\
\text { (Over 100M) }\end{array}$ & $\begin{array}{l}\text { Commercial } \\
\text { Service } \\
\text { Subscriber } \\
\text { (thousand) }\end{array}$ & - & - & - & 10 & 200 \\
\hline $\begin{array}{c}\text { Wireless } \\
\text { Broadband } \\
\text { (Average } 1 \mathrm{M} \sim 2 \mathrm{M})\end{array}$ & $\begin{array}{l}\text { Subscribers } \\
\text { (million) }\end{array}$ & $\begin{array}{c}22 \\
(0.3)\end{array}$ & $\begin{array}{c}28 \\
(0.8)\end{array}$ & $\begin{array}{l}32 \\
(5)\end{array}$ & $\begin{array}{c}40 \\
(12)\end{array}$ & $\begin{array}{c}46 \\
(18)\end{array}$ \\
\hline $\begin{array}{c}\text { Wireless } \\
\text { Ultra broadband } \\
\text { (Average 10M) }\end{array}$ & Establishment & - & - & - & $\begin{array}{c}\text { Nationwide } \\
\text { network }\end{array}$ & - \\
\hline $\begin{array}{l}\text { Wireless } \\
\text { Ultra broadband } \\
\text { (Average 10M) }\end{array}$ & $\begin{array}{l}\text { Commercial } \\
\text { Service } \\
\text { Subscribers } \\
\text { (million) }\end{array}$ & - & - & - & 0.3 & \\
\hline
\end{tabular}

test bed and equipped with 8 hubs at major cities in Korea by 2010. The interface specification of the public sensor network, such as weather, environment, disaster prevention safety and facility management, will be prepared and open to the public by 2012.

In addition to the enhancement of various networks, converged services will be discovered and developed. Interactive TV-based service (SoTV), mobile IPTV and MPS will be provided in Korea in 2012 through the two-way information ultra-highway. Interactive services to households will include education, healthcare, e-Government and e-Commerce as well as broadcasting and phone services. As the networks evolve towards ultra-broadband which is 10 times faster (1G for wired, $10 \mathrm{M}$ for wireless) than the existing broadband networks (100M for wired, $1 \mathrm{M}$ for wireless), more realistic services will be provided. MPS that combines the Internet, phone, and IPTV with mobile terminals for wireless environments will be provided. With the advance of network speeds, realistic multimedia contents can be delivered to homes, and it will be possible for subscribers to watch I-Max (Image Maximum) movies at home, the images of which are much clearer than full HDTV.

For now, the major killer services will be as follows: UDTV, mobile IPTV, mobile TPS, SoTV, and mobile VoIP. UDTV is a realistic broadcasting service, providing images which are $4 \sim 16$ times clearer than full HDTV. The UDTV service offers realistic moving picture contents as if the viewer at home were in a movie theater. It doubles the sense of presence by giving multiple viewpoint images from various angles within a movie and better video resolution. Mobile IPTV service and mobile VoIP services should be providing IP-based mobile services for broadcasting services and communication services respectively. Mobile TPS service will combine services for 


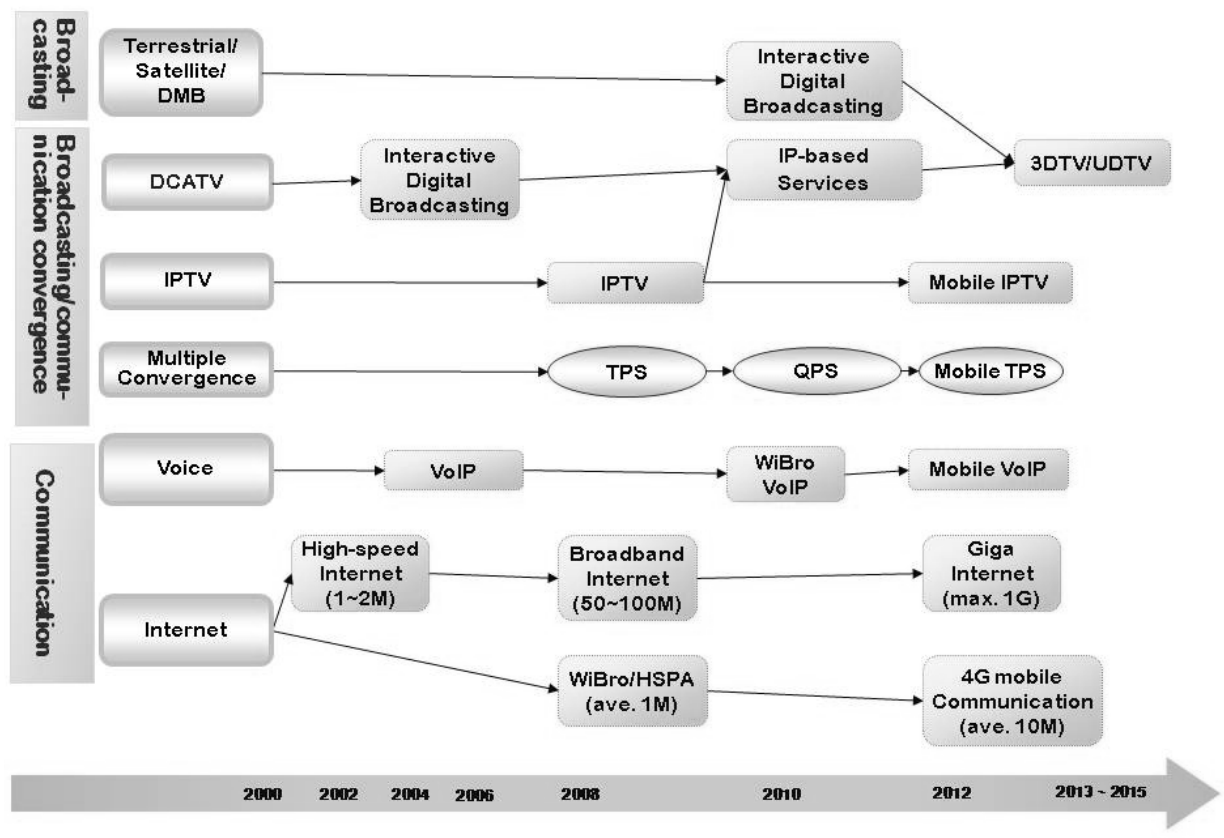

Fig. 2. Suggested UBcN Services

IP-based mobile phones, broadcasting, and the Internet. This service will offer '10 times faster speeds than the speeds available now' without interruption while moving. SoTV is an application service for interactive digital broadcasting such as TV-based education, health care, civil service, and e-Commerce. With TV-based education, lectures from schools and educational institutes are broadcasted in real time, and the service users are able to ask questions on the spot or purchase a text in the middle of the lectures. With the TV-based health care, the results of lab tests (e.g., blood pressure, pulse etc.) can be sent to a patient from a hospital to a TV at home. A patient can consult with a doctor, receive a prescription, and make a pharmacy purchase order through a TV at home on the spot. Figure 2 shows the suggested UBcN services and their development timeline.

\subsection{Development strategies}

To create the infrastructure and its supporting investment environment, 4 major directions of strategies are considered: promoting investment and network establishment, promoting network usage, efficient utilization of national communication resources and developing core technologies. In this section, the strategies to achieve the 4 major goals are discussed in detail. In addition to strategies to achieve the goals, the expected effects will be discussed at the end of the section.

Strategies for promoting the establishment of and investment in $\mathrm{UBCN}$ include developing a new service model, expanding $\mathrm{UBcN}$ to vulnerable areas such as rural areas, schools and libraries, improving the investment promotion policy, and preparing a map of UBcN information. Developing new service models such as killer services and conducting leading projects with the 
Table 3. The Draft of Funding Plan (unit: 100 million won)

\begin{tabular}{|c|c|c|c|c|}
\hline \multicolumn{2}{|c|}{ Network type } & $\begin{array}{c}\text { Phase } 1 \\
\text { (2009-2010) }\end{array}$ & $\begin{array}{c}\text { Phase2 } \\
\text { (2011-2013) }\end{array}$ & Total \\
\hline \multicolumn{2}{|c|}{ Backbone network } & 38,953 & 60,843 & 99,796 \\
\hline \multicolumn{2}{|c|}{ Service control } & 17,605 & 27,209 & 44,814 \\
\hline \multirow{2}{*}{$\begin{array}{l}\text { Service } \\
\text { network }\end{array}$} & Wire & 34,832 & 53,043 & 87,875 \\
\hline & Wireless & 34,705 & 56,313 & 91,018 \\
\hline \multicolumn{2}{|c|}{ Broadcasting network } & 2,084 & 2,785 & 4,869 \\
\hline \multicolumn{2}{|l|}{ Total } & 128,179 & 200,193 & 328,372 \\
\hline
\end{tabular}

models will promote the establishment of UBcN.

To expand broadcasting \& telecommunication networks to rural areas, broadcasting \& telecommunication service providers and government/private joint investors are obliged to set up networks in those areas. The government will support expanding the broadcasting \& telecommunication networks to all the schools and libraries. Table 3 shows a draft of the funding plan of the Korean government and private sectors.

Legal and political improvement can be another good strategy to promote the establishment of UBcN. For example, decreased taxes and increased loan support, and deregulation in broadcasting and telecommunication would stimulate the establishment of and the investment in $\mathrm{UBCN}$.

To encourage the use of $\mathrm{UBcN}$, first of all, interoperability and mobility will need to be improved. Information security will also need to be improved by fortifying quality management. The public sectors will be encouraged to use the UBcN to improve the quality of civil services. More users will utilize the $\mathrm{UBcN}$ with uninterrupted migration among various $\mathrm{UBcN}$ services, regardless of the user's location and terminal. The security of $\mathrm{UBcN}$ services can be improved by preparing the quality index/criteria of future $\mathrm{UBcN}$ services and by providing information security guidelines.

To increase the usage of UBcN networks, it is essential to strengthen the quality management systems and security systems of the UBcN network. For the developed new services, quality criteria and a quality measurement systems should be prepared. At the same time, a quality management system for future broadcasting \& telecommunication services must be established. For security, an information security management system such as information security guidelines must be set up. Methods of applying protection measures stage by stage are also required, and should be prepared.

Another good strategy to increase network usage is to support increased network utilization in the public sector. Application services for public areas, which would be based on UBcN networks, would improve the quality of the civil services. For example, public services such as IPTV, DCATV-based education and health care will improve the quality of the already-provided services, and it will result in the proliferation of integrated communication services.

The efficiency of national communication resources should be considered in the development of the UBcN. The methods for efficiently integrating the current network infrastructure and the new one must be prepared in order not to waste national resources. There needs to be a plan of 
implementing the joint formation and operation of the current system and new network for efficient utilization of the national communication resources. For this purpose, a method of promoting the current joint formation must be prepared. The current joint operation policy can be improved by re-adjusting the scope of the service providers' utilization. It is also necessary to prepare the joint formation and operation of the IP-USN and UBcN networks.

Last, but not least, is the strategy of developing core technologies of our own. Securing core technologies related with the UBCN will significantly increase our power of competition in the global broadcasting and telecommunication industry. The core technologies are related to the implementation of future network technologies and services, the integrated infrastructure, 4G mobile communication, and realistic and personalized interactive services. Along with developing new technologies, the testing and verification environments of new technologies should be supported. The establishment of open field test bed environments can be one of many good solutions. At the same time, standardization of the newly developed technologies must be considered. Without standardization, the new technologies cannot survive within the global market where many technologies emerge and disappear very quickly. Therefore, developing and propagating standards must be accomplished in line with providing new services. The status and the trends related with the $\mathrm{UBCN}$ should be surveyed and analyzed comprehensively and intensively, and international standardization activities should be conducted according to the surveys and analyses.

\section{EXPECTEd EfFects AND AsSessment}

\subsection{Expected effects}

Developing UBcN networks and related services is expected to bring about several positive effects on society and culture as well as the industry and economy of Korea. From an economic perspective, the development of the $\mathrm{UBcN}$ network and services will have a ripple effect on the national economy. Investment in the broadcasting and telecommunication networks will stimulate the required equipment industry, and it will also increase the level of employment and added value of the related industries. It is expected that the production inducement of the plan will amount to 48.5 trillion won, the added-value inducement will amount to 17.7 trillion won, and the employment inducement will amount to jobs for 126,000 persons.

In addition to stimulating the domestic economy, developing the $\mathrm{UBcN}$ network and services will create a new broadcasting and telecommunication industry based on the core technologies, and it will lead to improving our global competitiveness. Obtaining core technologies for the future network will enhance the technical competitiveness of Korea, and serve as shining examples of prosperity for other industries of Korea.

From a cultural point of view, developing the UBcN network and services will provide elegant and personalized broadcasting and telecommunication service, and the services will satisfy the diverse requirements of the public with ultra-broadband speed and guaranteed high quality. At the same time, the services based on fast and safe broadcasting and telecommunication networks will play an important role in resolving the problems of polarization, preventing disasters and improving the response speed for unexpected disasters. 


\subsection{Assessment and implications of the UBcN plan}

In this section, the implication of government-driven development plans will be discussed based on the author's experience in participating with formulating the $\mathrm{UBCN}$ development plan. I think that the successful development of the ICT infrastructure of Korea must be founded on the determination and active investment of the Korean government. I will present several facets for this sentiment in the later part of this section.

First of all, the leading policies of the Korean government to expand ICT infrastructure have been effective. The Korean government has advanced ICT infrastructure through preemptive policies since 1995. The policies include the establishment strategies for the high-speed information and communication network and broadband convergence network infrastructure. In conjunction with advancing the network infrastructure, the Korean government has arranged laws for new services of the improved networks, such as the "Internet Multimedia Broadcasting Service Law (IPTV)" and "Internet phone number mobility policy."

At the same time, the Korean government has made continuous investment in the public sector infrastructure. I assess that this decision has played quite an important role in the success of the series of plans because the governmental support for the advancement of the public sector infrastructure simultaneously generated the initial markets for the new services as well as the new network infrastructure. As a result, various online public services were developed. The most prominent example of the successful public services would be the e-Government civil service. The e-Government service of Korea is considered by many as very successful, and has since been exported to several developing countries as a reference model of e-Government.

After creating the initial markets, the Korean government successfully induced the voluntary participation of the private sector. This is the last, but not the least reason of the success of Korea's ICT policies. Based on the profit from the services in the public sectors, the private ICT companies were able to develop and invest new services for the public. The fact that Korea is one of the world' s most wired nations should be considered in evaluating Korea's network plans. More than $50 \%$ of the population of Korea lives in collective residential areas, so the residents of those residential buildings can be effectively serviced with high-speed networks. Compared with countries like the U. S., in which the larger parts of the population live in houses of the suburbs, Korea is in an advantageous position for the proliferation of high-speed information and communication networks; because the construction cost per subscriber in Korea is much smaller than other countries like the U. S..

The urgent problem which the Korean government must solve is the widening digital divide between rural areas and urban areas. The ratio of fast network infrastructure is much higher in urban areas than in rural areas because private ICT companies hesitate to invest in rural areas due to low cost-effectiveness. Considering the fact that the newly developed services are related to cultural and educational values, the wide digital divide will lead to problems of social divide. Since voluntary investment cannot be expected, governmental investment seems mandatory. Therefore, along with the direct financial support of network establishment costs for less prosperous areas, I suggest the creation and implementation of a loan policy to set up rural highspeed information and communication networks. 


\section{CONCLUSION}

The demand for converged, realistic, intelligent and personalized services is rapidly growing these days. It seems inevitable to develop a faster and more robust network infrastructure with effective strategies because the higher bandwidth required by these services is not provided by the current ICT infrastructure at all.

These converged services are considered the new growth engines of the ICT industries, so the Korean government has organized a multi-year plan for establishing a high speed next generation network, called an UBcN, as the new infrastructure network of Korea.

In this paper, the current status of high-speed broadband networks in Korea is analyzed, and Korea's development plan of an $\mathrm{UBcN}$ and their strategies are discussed. The main goal of the $\mathrm{UBcN}$ development is to establish an information and communications environment in which anybody can use converged network services anytime and anywhere. Six detailed plans among the major agendas of the $\mathrm{UBCN}$ have been explained, and the necessary strategies have been discussed. The author of this paper has taken part in formulating development plans since the early stages of planning. In this paper, the expected impact of the plans for the future ICT industry and the implications of government-driven development plans are analyzed and discussed based on the author's experience and knowledge acquired from such experience.

As one of the leading countries in the ICT industry, the deployed development plan of Korea is expected to set a positive example for other countries. I believe that the problems and technical challenges which will be encountered during the execution of the UBcN plan will provide a robust source for future research.

\section{REFERENCES}

[1] Basic blueprint for building the Broadband convergence Network, Ministry of Information and Communication of Korea, 2004.

[2] Second phase plan for establishing BcN, Ministry of Information and Communication of Korea, 2006.

[3] Third phase plan for establishing BcN, Ministry of Information and Communication of Korea, 2008.

[4] Broadband convergence Network Annual Report 2007, National Information Society Agency of Korea, 2007.

[5] A master plan for stimulating IPv6, Ministry of Information and Communication of Korea, 2007.

[6] IPv6 Status Report 2006, National Information Society Agency of Korea, 2007.

[7] A Study on the Implementation of the Next Generation Internet infrastructure, National Information Society Agency of Korea, 2007.

[8] YoungRo Lee, KyungSun Min et. al, A Business Development for the Digital Convergence Services based on BcN, NIA II-RIR-07044, NIA press, December 2007.

[9] JongHwa Yi, A Study on the Specification for BcN Service Interworking, NIA II-RIR-07086, NIA press, December 2007.

[10] Medium and Long-term Plan to Develop the Broadcasting and Telecom Network, Korea Communications Commission, January 2009. 


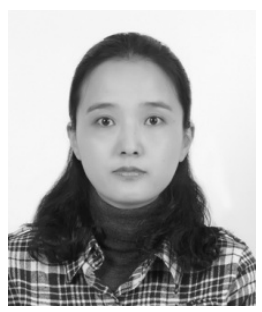

\section{EunYoung Lee}

She received a Ph.D. degree in Computer Science from Princeton University in 2004. She has been a professor at Dongduk Women's University since 2005. Her research interests are in the areas of High-Speed Network Management, Language-based Computer Security and Theory of Programming Languages. 